



\section{Uma edição digital do Leal Conselheiro de D. Duarte}
Autor(es):
Dionísio, João

Publicado por: Imprensa da Universidade de Coimbra

URL

persistente:

URI:http://hdl.handle.net/10316.2/30845

DOI:

DOI:http://dx.doi.org/10.14195/978-989-26-0218-9_4

Accessed : $\quad$ 26-Apr-2023 13:45:18

A navegação consulta e descarregamento dos títulos inseridos nas Bibliotecas Digitais UC Digitalis, UC Pombalina e UC Impactum, pressupõem a aceitação plena e sem reservas dos Termos e Condições de Uso destas Bibliotecas Digitais, disponíveis em https://digitalis.uc.pt/pt-pt/termos.

Conforme exposto nos referidos Termos e Condições de Uso, o descarregamento de títulos de acesso restrito requer uma licença válida de autorização devendo o utilizador aceder ao(s) documento(s) a partir de um endereço de IP da instituição detentora da supramencionada licença.

Ao utilizador é apenas permitido o descarregamento para uso pessoal, pelo que o emprego do(s) título(s) descarregado(s) para outro fim, designadamente comercial, carece de autorização do respetivo autor ou editor da obra.

Na medida em que todas as obras da UC Digitalis se encontram protegidas pelo Código do Direito de Autor e Direitos Conexos e demais legislação aplicável, toda a cópia, parcial ou total, deste documento, nos casos em que é legalmente admitida, deverá conter ou fazer-se acompanhar por este aviso.

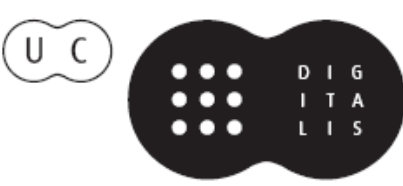


Marta Teixeira Anacleto e Elsa Branco

Coordenação

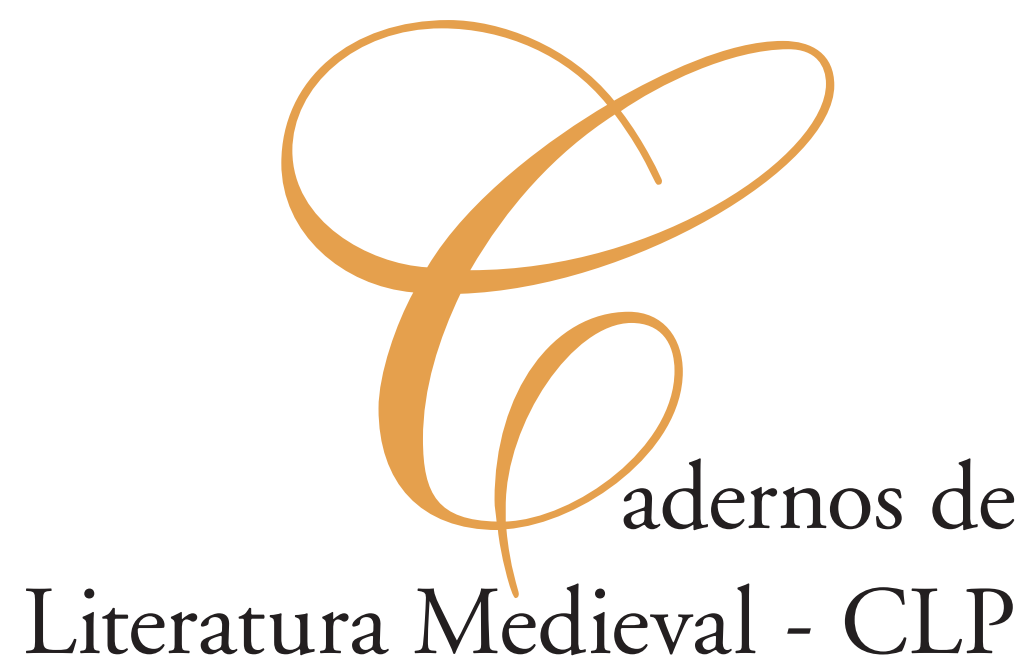

A Prosa Didáctica Medieval 


\section{João Dionísio}

Centro de Linguistica da Universidade de Lisboa

Faculdade de Letras da Universidade de Lisboa

\section{UMA EDIÇÃO DIGITAL DO LEAL CONSELHEIRO \\ DE D. DUARTE}

A nova edição do Leal Conselheiro, de D. Duarte, que apresento de seguida, resulta de uma parceria entre a Biblioteca da Faculdade de Letras da Universidade de Lisboa, o Centro de Linguística da Universidade de Lisboa e a Universidade de Wisconsin - Madison (General Library System, UW Digital Collections e o Department of Spanish and Portuguese). Os trabalhos começaram formalmente depois da assinatura de um memorando de entendimento em Outubro de 2008.

O objecto de trabalho é o tratado moral que D. Duarte (1391-1438) procurou compilar no final do seu reinado. Neste tratado foram reunidos textos avulsos que existiam previamente à ideia de fazer um livro e para ele foram encaminhados outros textos redigidos de propósito para fazerem parte do Leal Conselheiro. Desta obra conserva-se um único testemunho dotado do texto integral, guardado na Biblioteca Nacional de França com a cota Portugais 5, e que também contém a única cópia sobrevivente de outra obra de D. Duarte, o manual de equitação com o título Livro da Ensinança de Bem Cavalgar Toda Sela 1 . O Leal Conselheiro é dedicado à mulher de D. Duarte, D. Leonor de Aragão, a comitente e dedicatária da obra (como diz o incipit: «trautado [...] o qual fez Dom Eduarte [...] a rrequerimento da muyto excellente Reynha dona Leonor, sua molher» ${ }^{2}$ ). Sendo seguro que o único códice subsistente entrou em território francês no início do século XVI, senão mesmo já no final do século anterior, a explicação mais completa para o percurso do manuscrito desde que

\footnotetext{
${ }^{1}$ http://sunsite.berkeley.edu/Philobiblon/BITAGAP/1154.html.

2 Todas as citações são retiradas da edição preparada por Joseph M. Piel, 1942, na qual foram introduzidas correcções quando necessário.
} 
terá saído de Portugal até chegar a França não é isenta de incertezas (cf. Castro, 1995 e Castro, 1998). Valerá a pena, em especial, reavaliar a cota que se encontra sob a coluna exterior do último fólio, $128 \mathrm{r}^{3}$ :



Seja qual for a interpretação dada a esta cota, o manuscrito permaneceu aparentemente sem leitores durante séculos na Biblioteca Régia de França até ser descoberto pelo Abade José Correia da Serra (Bourdon, 1979). As duas primeiras ediçōes, sensivelmente contemporâneas, vieram a lume em meados do séc. XIX: a de José Inácio Roquette e do Visconde de Santarém, saída em Paris, J. P. Aillaud, com data de 1842 (embora deva ter começado a circular em 1843), e a conhecida como da «Typographia Rollandiana», de Lisboa, publicada em 1843. Como assinala Piel, a edição Rollandiana tem por fito uma reprodução muito próxima do que se encontra no manuscrito, embora apresente várias lições que não são fiáveis, ao passo que a edição de Roquette contém «arbitrariedades na transcrição e modernizações intoleráveis», além de "numerosíssimos erros de leitura» e faltas de períodos (Piel, 1942: XXI-XXII). Aliás, as faltas chegam ao ponto de um capítulo inteiro ter sido omitido, lacuna que contribuiu para o aparecimento de nova edição de Roquette em 1854, com o acrescento do texto em falta em paginação autónoma ${ }^{4}$. A primeira edição

${ }^{3}$ Maria Helena Lopes de Castro dá por seguro que este sinal corresponde a uma cota utilizada na biblioteca de Afonso V de Aragão e Nápoles. Segundo informação pessoal transmitida por Gennaro Toscano (11.3.2007), a cota poderia ter sido feita depois da conquista de Nápoles em 1495 por Carlos VIII de França ou pode ser já uma cota da biblioteca de Blois, onde o códice permaneceu antes de ir para a biblioteca régia francesa.

${ }^{4} \mathrm{O}$ capítulo LV vem impresso na edição de 1854 nas páginas 310a, 310b, 310c e 310d, entre as páginas 310 e 311. 
crítica sai quase um século mais tarde e é devida a Joseph M. Piel, o qual, contudo, não pôde trabalhar directamente sobre o manuscrito, só tendo contado com uma cópia fotográfica de qualidade bastante insatisfatória para os padrões actuais. Trabalho que ainda hoje, apesar de algumas falhas, é um marco de qualidade na transmissão do texto eduardino, a edição Piel está na base da chamada edição Manuel Lopes de Almeida (na realidade, um descriptus indiferente da edição Piel) e da edição com modernização ortográfica feita por João Morais Barbosa (que actualiza com critérios discutíveis e fornece anotação maioritariamente dependente das observaçôes de Piel). Finalmente, em 1998 é publicada uma nova edição crítica, da responsabilidade de Maria Helena Lopes de Castro, que teve a possibilidade de consultar directamente o manuscrito e pôde assim corrigir alguns lapsos cometidos pelo filólogo alemão. Trabalho abonado com notas relevantes acerca das características materiais do códice, a edição Lopes de Castro não retomou, contudo, as muito úteis anotações acerca das fontes que constam da edição Piel (Dionísio, 2001b).

Feito de maneira brevíssima o historial das edições do Leal Conselheiro, há um tipo editorial que ainda não foi experimentado, faltando por isso no campo bibliográfico do texto de D. Duarte: a edição digital. Os objectivos estabelecidos para esta edição digital são ultrapassar os limites impostos pelo formato «livro» usando três planos de representação do texto: 1) o plano da imagem através da representação digital de grande qualidade do manuscrito; 2) o plano documental através de uma transcrição diplomática muito conservadora; 3) o plano «normalizado» por meio de uma edição crítica. Ficam algumas notas sobre cada um destes aspectos.

Quanto ao plano da imagem, os primeiros antecedentes são os que serviram para o trabalho de Joseph Piel. Em 15 de Junho de 1934, a Comissão Executiva da Junta da Educação Nacional autorizou que fosse utilizada uma verba de 876.60 francos franceses para a compra das «foto-cópias» do Leal Conselheiro (Campos: V). O preço acabou por ser aliviado devido à decisão tomada pelo Professor Le Gentil, que achou oportuno ordenar a reprodução de duas páginas, no lugar de uma, por cada chapa fotográfica. Como apontou Agostinho de Campos, «baixava assim o preço da reprodução, mas com prejuízo da leitura» (Campos: VI), o que afectou o estabelecimento crítico da obra proposto por Joseph Piel. O primeiro microfilme, a preto e branco, disponível para consulta pública em Portugal veio a ser feito pela Biblioteca Nacional de Lisboa por ocasião da exposição realizada em 1999, A Iluminura em Portugal. 
Identidade e Influências, de que foi comissária Adelaide Miranda 5 . Por fim, a parceria que tem em curso a presente edição electrónica obteve autorização em Dezembro de 2008, graças à diligência e amabilidade de Arnaud Beaufort (Directeur général adjoint e Directeur des services et des réseaux da Biblioteca Nacional de França), para usar uma cópia digital de alta qualidade, que espera poder integrar no resultado consultável do projecto. Esta cópia foi oferecida antes da disponibilização de uma outra cópia de resolução mais baixa para o portal Gallica ${ }^{6}$.

No que diz respeito ao plano da transcrição diplomática, o objectivo é representar o texto de acordo com o seguinte procedimento geral explicado pelo Menota Handbook. Guidelines for the electronic encoding of Medieval Nordic primary sources: "the text is transcribed character for character, line for line. Allographic variation is to a great extent reflected in the transcription and abbreviation marks are copied without any expansion» 7 . Apesar de a edição Rollandiana procurar obedecer a um programa de transcrição muito conservador, o antecedente mais nítido, com diferenças que não interessa assinalar nesta ocasião, encontra-se, no que se refere ao Leal Conselheiro, no álbum de paleografia preparado por John M. Burnam, Palaeographia Iberica.

Em relação ao plano da edição crítica, as interlocutoras principais do presente projecto são evidentemente a edição realizada por Joseph Piel e a de Maria Helena Lopes de Castro.

Podemos, assim, dizer que o projecto assenta numa base tripartida:

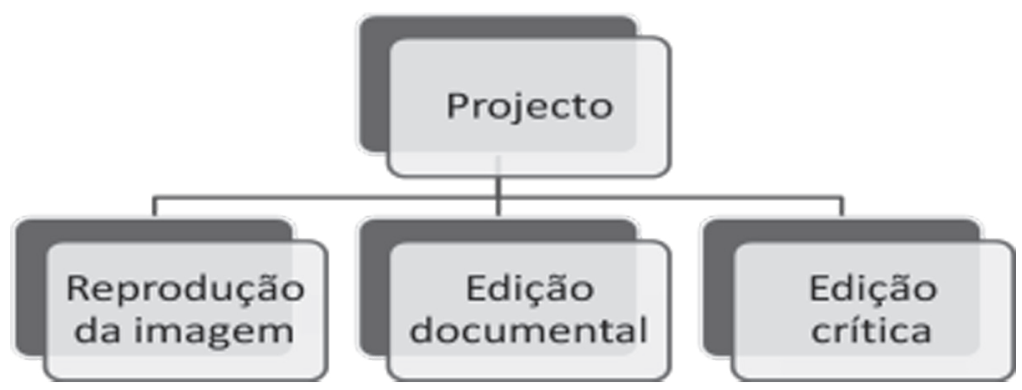

${ }^{5}$ De acordo com consulta aos sistemas BNP em 31.1.2010, o microfilme, que pertence ao Fundo Geral Monografias, tem a cota em processamento.

${ }^{6}$ http://gallica.bnf.fr.

7 http://www.menota.org/guidelines/ch3/levels_1-1.html. 
Estas três zonas da edição não serão estanques, antes comunicando umas com as outras através da possibilidade oferecida ao utilizador de navegar entre elas. Portanto, fará talvez mais sentido representar a base do projecto assim:

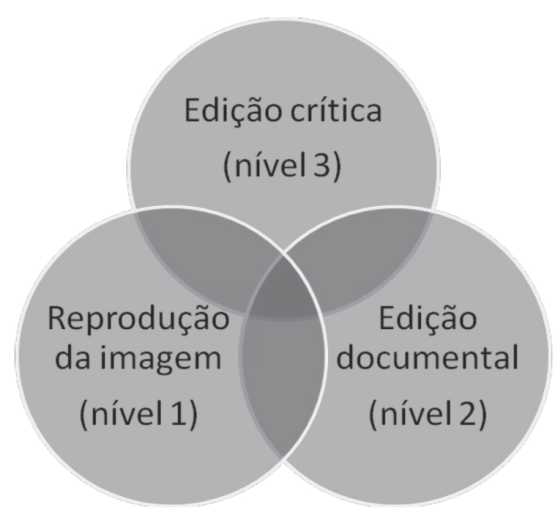

Apresentados os fundamentos desta edição digital, importa agora mostrar como o projecto se ramifica por territórios adjacentes e complementares. Observe-se o esquema seguinte no qual a base do projecto está representada no meio, encontrando-se a ela subordinadas as outras secções da edição.

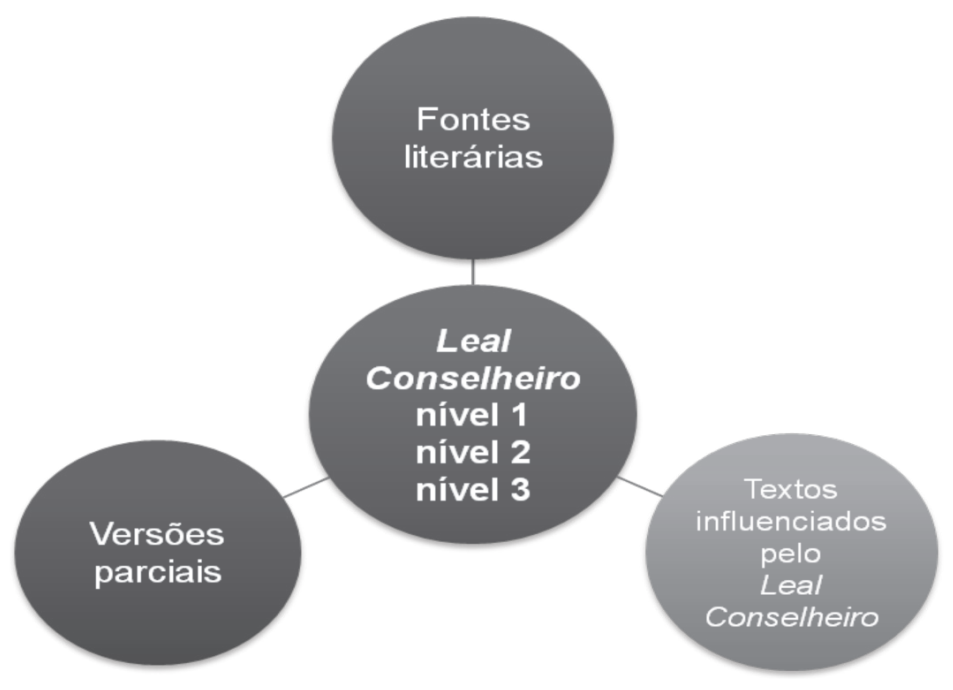


Versões parciais: embora o manuscrito Portugais 5 seja o único testemunho sobrevivente com o texto integral do Leal Conselheiro, existem alguns códices medievais e posteriores que transmitem versões de capítulos ou de partes de capítulos incluídos no tratado de D. Duarte. Estas versôes corresponderão em vários casos às reflexões esparsas a que $\mathrm{D}$. Leonor terá tido acesso antes de animar D. Duarte a fazer a compilação do que é o Leal Conselheiro. Os fólios de códices localizados com estas versões serão reproduzidos e o seu texto será transcrito e editado nesta nova edição (para o elenco destes testemunhos, cf. Dionísio, 2000; Dionísio, 2001a).

Fontes literárias: quando estava a escrever as reflexões esparsas e, depois, quando redigiu capítulos concebidos de propósito para figurarem no seu tratado moral, D. Duarte serviu-se de um número considerável de fontes literárias, que são citadas de forma mais ou menos extensa, mais ou menos reconhecível. Em função disto, o Leal Conselheiro ganha em ser lido à luz das fontes que para ele foram convocadas, condição para se perceber o grau de inovação e reelaboração da escrita do autor em relação aos seus materiais de partida. Por isso, o projecto de edição digital incorporará transcrições de todos os trechos identificados como tendo sido lidos e utilizados por D. Duarte na redacção da sua obra (Dionísio, 2000).

Textos influenciados pelo Leal Conselheiro: apesar de dispormos de vários sinais que dão a entender que este tratado foi lido raramente até o códice da Biblioteca Nacional de França ter sido encontrado no início do séc. XIX, existem uns poucos vestígios da influência que exerceu nalguma cronística medieval portuguesa, designadamente na Crónica de D. João I, escrita por Fernão Lopes, e na Crónica da Conquista de Ceuta, redigida por Gomes Eanes de Zurara. Também estes textos que exibem marcas da leitura do Leal Conselheiro serão reproduzidos na edição digital.

O gráfico seguinte procura mostrar como as diferentes zonas do arquivo se relacionam umas com as outras, indicando-se os níveis de representação que serão considerados em cada uma delas. Note-se que, tanto no campo das fontes literárias como no campo dos textos influenciados pelo Leal Conselheiro, será disponibilizada uma transcrição na maior parte dos casos normalizada, extraída sobretudo das edições de referência. Já no campo do texto e no das versões parciais serão oferecidas, sempre que possível, reproduções das imagens dos manuscritos pertinentes, uma transcrição diplomática e uma fixação crítica: 


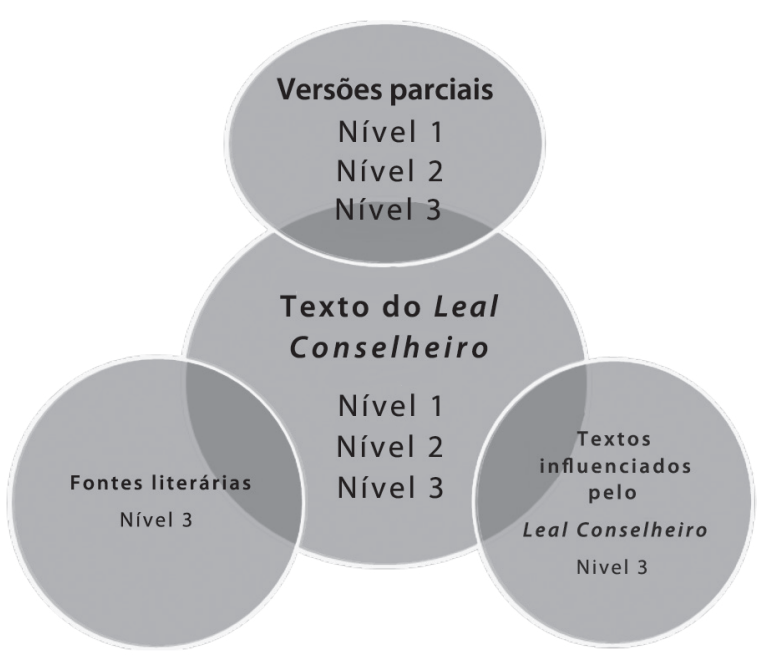

Para a concretização deste projecto foram constituídos dois grupos de trabalho: um em Madison, coordenado por Paloma Celis-Carbajal, que inclui Jason Doroga e, numa fase inicial, Laura Schmidli, depois substituída por William Straub; outro em Lisboa, coordenado por Pedro Estácio (chefe de divisão da Biblioteca da Faculdade de Letras da Universidade de Lisboa) e por mim próprio, que inclui três colaboradoras seleccionadas através do programa de voluntariado da Biblioteca da FLUL: Ana Filipa Neves, Marta Grachat e Sílvia Pedro.

Os dois grupos procederam até agora à etiquetagem estrutural do texto através da linguagem de marcação mais expandida na área das Humanidades, a TEI, tendo sido usada a versão $\mathrm{P}^{8}$. Significa isto, por exemplo, que todo o Leal Conselheiro foi segmentado em cláusulas de modo a que possam ser estabelecidas conexões entre troços precisos dos textos disponibilizados nas diferentes secções da edição digital. Esta é apenas uma das medidas que visam contribuir para ultrapassar os três grandes desafios que a presente edição enfrenta: 1. Dificuldade de acesso ao texto; 2. Preconceito proprietário no estabelecimento crítico; 3 . Cristalização do estabelecimento crítico.

${ }^{8}$ http://www.tei-c.org/Guidelines/P4/. 
1. Além das dificuldades de leitura e compreensão colocadas por uma obra escrita num português típico do dealbar da prosa conceptual da Literatura de Avis, há dificuldades de acesso ao Leal Conselheiro resultantes de a única edição integral actualmente ainda disponível no mercado ter uma distribuição insuficiente. Com esta proposta de uma edição digital, tanto o texto como a marcação sobre ele aplicada serão disponibilizados em acesso inteiramente livre.

2. O que costuma acontecer na história das edições de uma obra é que o editor seguinte selecciona o melhor do trabalho de quem o antecedeu, actualizando-o com aperfeiçoamentos no estabelecimento crítico. $\mathrm{Na}$ edição electrónica não só será possível o reconhecimento individual de cada editor, desde Roquette até à actualidade, pelo contributo dado para o conhecimento do texto, como serão bem-vindos contributos de utilizadores da edição electrónica. Aliás, todas as sugestôes de alteração consideradas pertinentes serão devidamente registadas e atribuídas nominalmente.

3. Finalmente, ao contrário do que sucede no formato «livro», a fixação crítica resistirá facilmente à cristalização, estando prevista no memorando de entendimento assinado pelas partes envolvidas neste projecto uma actualização semestral da edição electrónica.

Gostaria de terminar, dizendo que os resultados do projecto serão alojados na colecção Ibero-American Electronic Text Series, no âmbito das colecções digitais da Universidade de Wisconsin ${ }^{9}$, e, em Portugal, no Portal da Universidade de Lisboa ${ }^{10}$ e na Biblioteca Digital da Faculdade de Letras ${ }^{11}$.

\footnotetext{
${ }^{9}$ http://digicoll.library.wisc.edu/IbrAmerTxt/.

10 http://www.ul.pt/portal/page?_pageid=173,1\&_dad=portal\&_schema=PORTAL.

11 http://www.fl.ul.pt/biblioteca/biblioteca_digital/index.htm.
} 